\title{
Surface Cleaning of Metals Using Low Power Fiber Lasers
}

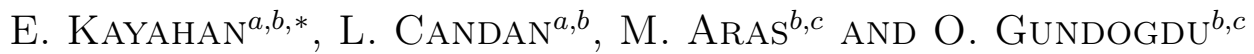

${ }^{a}$ Kocaeli University, Electro-Optics and Systems Engineering, Umuttepe, 41380, Kocaeli, Turkey

${ }^{b}$ Kocaeli University, Laser Tech. Res. Center-LATARUM, 41275, Teknopark, Yenikoy, Kocaeli, Turkey

${ }^{c}$ Kocaeli University, Technology Fac. Biomedical Eng. Umuttepe, 41380, Kocaeli, Turkey

Lasers are used in industry in a large variety of applications. These applications can mainly be divided into two categories: one specifically being materials processing. Material processing includes cutting, drilling, welding, etc., and generally involves the use of high-powered lasers. Laser applications such as rust/dye removal and surface cleaning are not yet very common for the industry. This paper reports experiments on industrial applications of a low-power fiber laser $(20 \mathrm{~W})$. Experimental studies showed that a low-power fiber laser could be used for a variety of applications such as surface cleaning of metals and rust-dye removal. Optimum laser parameters were also determined for these applications.

DOI: 10.12693/APhysPolA.134.371

PACS/topics: fiber laser, metal surface, laser-assisted cleaning

\section{Introduction}

Lasers have found numerous rather successful applications in industry in recent years with emphasis being on cutting, drilling, and welding of metals employing highpower lasers over the power of $500 \mathrm{~W}$ [1].

Surface cleaning is also becoming increasingly important in modern manufacturing as lasers interact with materials differently. When the laser power is increased material surface gets heated due to heat absorption and conduction depending on material properties [1]. When the laser power is sufficient enough to increase the temperature of the surface, it begins to melt, turning from a solid to a liquid. If the power is considerably higher, the material may directly vaporise, hence into a gas phase. Each of these processes is used for different purposes i.e. drilling, welding and cutting. There are many studies where high-power lasers are used for industrial applications reported in literature related to welding, drilling, and cutting of metals [2, 3]. However, low-power lasers less than $100 \mathrm{~W}$ could also be used for different industrial purposes. Laser cleaning of metal surfaces, for example, needs a low-power laser. The low-power laser applications such as laser cleaning of metal surfaces have grown enormously in literature [3-6].

Experimental studies performed to remove dye and contaminants from material surfaces, using a low-power fiber laser are hereby presented in this paper with a focus on industrial applications. The applications have not been used in industry yet. The aim of this study is to show that low-power fiber lasers can also be used for further industrial applications.

\section{Experimental}

The surface cleaning studies were carried out with a commercially available industrial itterbium fiber laser

\footnotetext{
*corresponding author; e-mail: kayahan@kocaeli.edu.tr
}

(1064 nm) with a maximum output power of $20 \mathrm{~W}$ pulse duration of $200 \mathrm{~ns}$ and pulse repetition rate of 10 $100 \mathrm{kHz}$. The system was equipped with a galvanometric scan mirror that allows the laser beam to move in a raster fashion. A special computer program was used for controlling the galvo-head (scan-head) and to input laser parameters. The laser beam was focused on the target through a $160 \mathrm{~mm}$ focal length $\mathrm{F}-\mathrm{T}$ lens.

TABLE I

Optimum laser and scan parameters for surface treatment using the fiber laser

\begin{tabular}{l|c|c|c|c}
\hline \hline & \multicolumn{2}{|c|}{ Laser parameters } & \multicolumn{2}{c}{$\begin{array}{c}\text { Scan parameters } \\
\text { using scan head }\end{array}$} \\
\cline { 2 - 5 } & $\begin{array}{c}\text { Average } \\
\text { power [W] }\end{array}$ & $\begin{array}{c}\text { Repetition } \\
\text { rate }[\mathrm{kHz}]\end{array}$ & $\begin{array}{c}\text { Scan } \\
\text { speed [mm/s] }\end{array}$ & $\begin{array}{c}\text { Line } \\
\text { spacing [um] }\end{array}$ \\
\hline mold cleaning & 18 & 50 & 80 & line \\
paint removing & 10 & 20 & 80 & 50 \\
rust removing & 10 & 50 & 80 & 100 \\
dirty cleaning & 15 & 40 & 80 & 50 \\
truck removing & 20 & 90 & 10 & 10
\end{tabular}

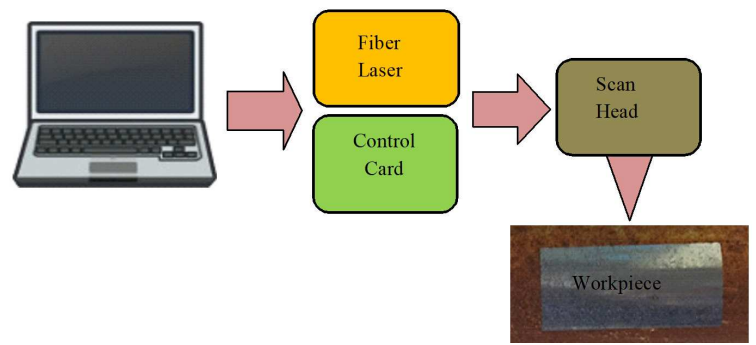

Fig. 1. Schematic diagram of the low fiber laser processing.

Dirty, painted, and rusty metal surfaces with different properties were cleaned using a fiber laser. The metal surfaces are scanned by the laser beam with different experimental parameters such as scan velocity, laser 
power, and line spacing. Used experimental parameters are shown in Table I, where line spacing and scan speeds of the laser are 1-100 $\mu \mathrm{m}$ and $3-100 \mathrm{~mm} / \mathrm{s}$, respectively. Figure 1 also shows the experimental setup schematically. The laser polishing experiments are carried out in air, at room temperature and no shielding gas was used.

\section{Results and discussion}

\subsection{Dirt removal from metal mold surfaces}

Mold surface cleaning is a process where major maintenance bottlenecks occur as molds are usually pulled faster than they can be cleaned and made productionready $[7,8]$. Cleaning mold plates and re-tooling are usually more tedious, time-consuming, and labour intensive than any of the other repair stages (disassembly, troubleshooting, or reassembly) combined [7]. A new approach is needed to realise a major reduction in the time required to clean molds, to maximize tooling life, to make cleaning more systematic, consistent and predictable [8, 9]. Laser cleaning technology for the mold surfaces would, therefore, be a more suitable technology for this purpose.

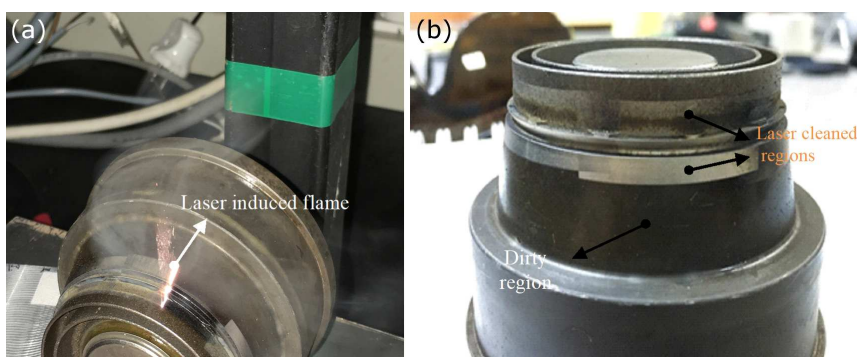

Fig. 2. Mold cleaning by the laser: (a) during the laser processing and (b) is after the part cleaning processing.
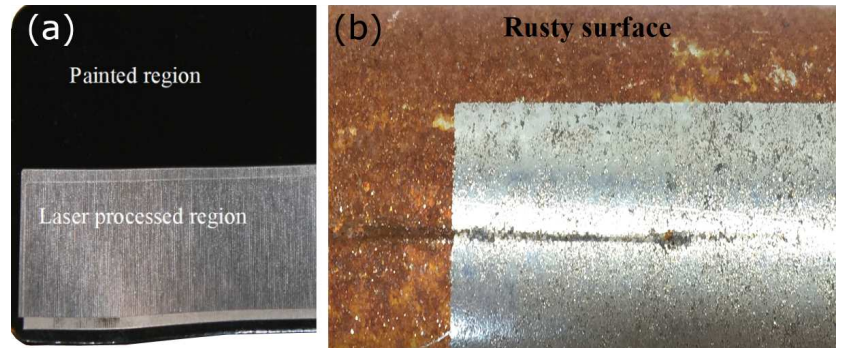

Fig. 3. (a) Paint removal and (b) rust removal using fiber laser on a metal surface.

Figure 2 shows the surface cleaning of a plastic injection mold by a low-power fiber laser during the process and after the laser treatment. As seen in the figure, production and environmental dirt which are industrial oil, petroleum oil could easily be removed by the laser cleaning from the mold surface without causing the loss of the base metal. The metal surface is turned to an original state of the surface after the processing. The method is also eco-friendly, fast and with the least amount of damage to the original surface.

\subsection{Rust and paint removal from metal surfaces}

Rust is a redox reaction of metal and oxygen that involves the exchange of electrons between atoms. Certain chemicals can accelerate rusting by increasing the electrical activity between iron and oxygen. Steel is an alloy that includes iron and is used virtually everywhere, so oxidation (rusting) occurs in air in the presence of moisture and the surfaces must be cleaned prior to use. The painted and rusty surfaces are usually cleaned using sanding. However, lasers can be used as paint and rust remover as seen in Fig. 3. Figure 3A shows removing of paint on aluminium surface after the laser treatment. Figure 3B also shows rusted and cleaned metal surface. As seen in the figure rust and paint with a thickness of $1 \mathrm{~mm}$ were removed from metal surfaces using the laser.
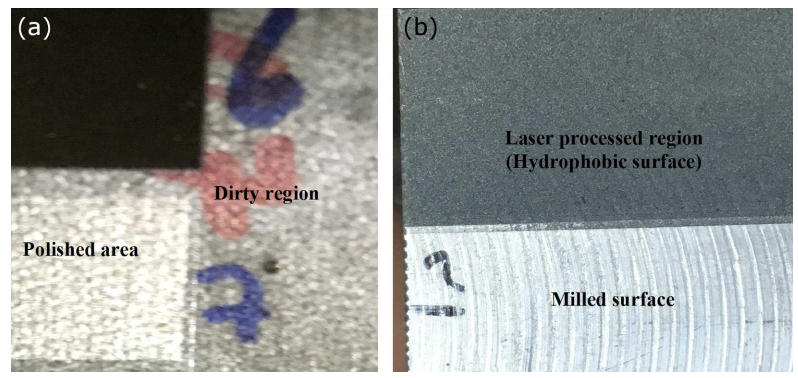

Fig. 4. (a) Polishing of GGG70 surface and (b) is the hydrophobic surface of the AA7075 surface using the fiber laser.

\subsection{Polishing of $G G G$ surface and hydrophobicity on AA7075 surface}

Spherical graphitic cast iron (nodular cast iron-GGG) is mostly used in mold industry. Moreover, polishing of mold surfaces and obtaining desired roughness values on the surface are very important. Molds especially used in the glass/optical industry should preferably have as smooth surfaces as possible since it affects the quality of the finished product. Similarly, the automotive industry also wants smooth and bright surfaces. Mold surfaces must, therefore, be cleaned and polished after a pre-determined or certain time. Lasers can be used to polish and clean mold surfaces. Figure 4a shows polished GGG70 surface using a fiber laser. The low-power fiber laser can also be used to remove milling trucks on face milled aluminium surfaces as seen in Fig. 4b. In addition, a hydrophobic surface is also obtained on the aluminum surface after the laser processing.

Contamination in metal layers (dust, paint, oil, etc.) is removed based on pulsed laser ablation. With laser radiation being strongly absorbed within the contamination layer, pulsed-laser ablation permits one to remove 
such layers with pulses [1]. Optical properties of this layers (dust, paint, and dirty) hence are different from bulk materials. Therefore, this layer can be easily removed from metal surface. This is a very important property of the cleaning technique and a prerequisite for the applications. Furthermore, contrary to mechanical tools or chemical techniques, laser light avoids any contamination of the material being processed. Removing of the milling patterns from the metal surface also can be explained through roughening by re-melting instead of ablation as mentioned in our previous study [10].

\section{Conclusions}

In this study, we explored further industrial applications of low power fiber lasers and optimum experimental parameters were determined. Our experimental studies showed that fiber laser can be used as a surface cleaner, paint and dust remover from metal surfaces. Fiber laser processing also allows us to obtain a hydrophobic surface which would have further, wide-ranging crucial applications. However, there is a need to develop scan heads for use on large metal surfaces. It is hoped that these studies will lead to the development of a hand-held purpose built with proper optical and laser systems for a variety of industrial processes.

\section{Acknowledgments}

This research has been supported by The Scientific and Technological Research Council of Turkey (TÜBİTAK). Project No. 5175001.

\section{References}

[1] D. Bauerle, T. Gumpenberger, D. Brodoceanu, G. Langer, J. Kofler, J. Heitz, K. Piglmayer, in: Laser Cleaning II, Ed. D.M. Kane, World Sci., 2006, p. 1.

[2] Kyung-Min Hong, Yung C. Shin, J. Mater. Process. Technol. 245, 46 (2017).

[3] J. Lawrence, L. Li, in: Micro and Nano Manufacturing, Advances in Laser Materials Processing Ed. J. Lawrence, Woodhead Publ., 2018, p. 23.

[4] T. Palomar, M. Oujja, I. Llorente, B. Ramírez Barat, M.V. Canamares, E. Cano, M. Castillejo, Appl. Surf. Sci. 387, 118 (2016).

[5] G. Buccolieri, V. Nassisi, A. Buccolieri, F. Vona, A. Castellano, Appl. Surf. Sci. 272, 55 (2013).

[6] E. Drakaki, A.G. Karydas, B. Klinkenberg, M. Kokkoris, A.A. Serafetinides, E. Stavrou, R. Vlastou, C. Zarkadas, Appl. Phys. A 79, 1111 (2004).

[7] J. Padma Nilaya, M.B. Sai Prasad, Dhruba J. Biswas, Appl. Surf. Sci. 263, 25 (2012).

[8] S. Johnson, Cleaning Molds: Part II, MoldMaking Technology, 2004, access time 23 Oct 2017.

[9] S. Johnson, Cleaning Molds: Part I, Plastics Technology, 2007 access time 23 Oct 2017.

[10] E. Kayahan, Opt. Laser Technol. 101, 440 (2018). 